Proceedings

\title{
Protecting Children in Pakistani Cyberspace: Technology-Religion Education Safety Approach ${ }^{\dagger}$
}

\author{
Naeem Abas 1,*, Farhat Naseem ${ }^{2}$, Ali Raza Kalair ${ }^{3}$ and Muhammad Shoaib Saleem ${ }^{4}$ \\ 1 Department of Electrical Engineering, University of Gujrat, Hafiz Hayat, Gujrat 50700, Pakistan \\ 2 Munk School of Global Affairs \& Public Policy, University of Toronto, Toronto, ON M5S 1A1, Canada; \\ farhat.naseem@utoronto.ca \\ 3 Department of Electrical Engineering, COMSATS Institute of Information Technology, Islamabad 44000, \\ Pakistan; ali.kalair.ak@gmail.com \\ 4 Department of Electrical Engineering, University of Management and Technology Lahore, Sialkot Campus, \\ Sialkot 51310, Pakistan; muhammad.shoaib@skt.umt.edu.pk \\ * Correspondence: naeemkalair@uog.edu.pk; Tel.: +92-300-5879-115 \\ + Presented at the 2nd Innovative and Creative Education and Teaching International Conference \\ (ICETIC2018), Badajoz, Spain, 20-22 June 2018.
}

Published: 29 October 2018

\begin{abstract}
Internet, mobile phones, computer games and electronic media are seriously affecting minor as well as younger children worldwide. This work describes the fundamental reasons for children protection in cyberspace and suggests critically essential recommendations to Pakistani Anti-Cyber Crime Law to take necessary initiatives to protect children in no man's land-the cyberspace. This work incorporates technological support to protect young ones in ephemeral space.
\end{abstract}

Keywords: cyberspace; Webopedia; Symantec; Microsoft; information technology (IT)

\section{Cyberspace}

Cyberspace is the global domain of electromagnetic (EM) data accessed through electronic technology and exploited through the modulation of EM energy to achieve a wide range of communication and control system capabilities. Cyberspace allows the interdependent network of information technology (IT) infrastructures, telecommunications networks-such as the internet, computer systems, integrated sensors, system control networks and embedded processors and controllers common to global control and communications [1-3]. As a social experience, individuals can interact, exchange ideas, share information, provide social support, conduct business, direct actions, create artistic media, play simulation games and engage in political discussions. While cyberspace should not be confused with the real internet, the term is often used to refer to objects and identities that exist mainly within the communication network." [4]. Cyberspace may be regarded as the so-called virtual world provided by the internet, the online world-wide-web, computer networks and systems. It also includes mobile phones, dish or cable TV, offline video games and simulation games. Cyberspace may be regarded as an ephemeral space where ideas and information are transmitted and exchanged. Cyberspace is a virtual world built on physically tangible materials.

According to Webopedia, the cyberspace is a metaphor for describing the non-physical terrain created by computer systems. Online systems, for example, create a cyberspace within which people can communicate with one another (via e-mail), do research, or simply window shop. Like physical space, cyberspace contains objects (files, mail messages, graphics, etc.) and different modes of transportation and delivery. Unlike real space, though, exploring cyberspace does not require any physical movement other than pressing keys on a keyboard or moving mouse. Some programs, particularly computer games, are designed to create a unique cyberspace, one that resembles physical 
reality in some ways but defies it in others. In its extreme form, called virtual reality, users are presented with visual, auditory, and even tactile feedback that makes cyberspace feel real. TV (1926), computer (1936), internet (1972) and mobile phone (1985) are the implements of so-called electronic media. Famous fiction writer William Gibson coined the word "Cyberspace" and used it firstly as a buzzword in his novel Neuromancer in 1984. Implements of modern cyberspace are shown in Figure 1.

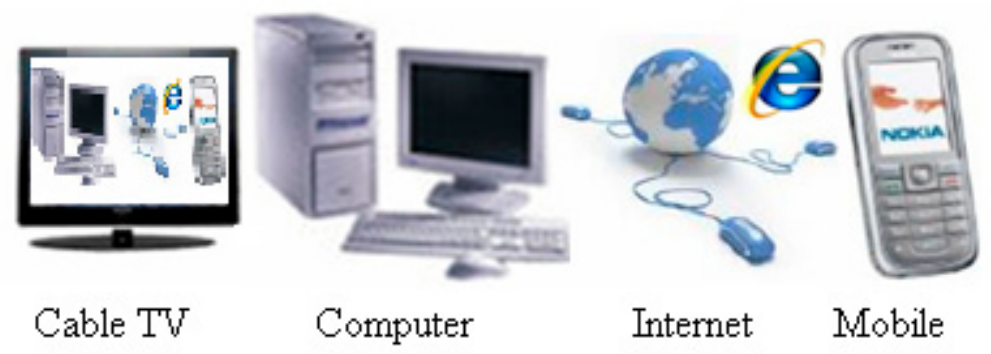

Figure 1. Implements of cyberspace.

By the start of 21st-century electronic messages were being sent at a rate of 9.8 billion per day. Online shopping exceeded $\$ 117$ billion per year in 2004. There were 92 million websites by 2006 . Microsoft offered to buy Yahoo for $\$ 44.6$ billion in 2008. Microsoft was fined twice total $\$ 2.5$ billion for violating cyberspace. To an estimate more than $40 \%$ of users are children, $35 \%$ users are greenhorn researchers and remaining $25 \%$ users are grey hair men and women. The telecom engineers started worrying about electronic limitations of the semiconductor materials, but photonics engineers have held the flag to meet the high data rate requirements by the start of 21st century. World community has started demanding THz bandwidth in 2009 that is likely to increase to PHz by 2020 [5]. Industrial (1750), agriculture (1950) and the information technology (1990) revolutions have brought prosperity and change in lifestyle. Information and Communication Technologies (ICT) are so fast changing our daily routines the old time's educated people to find difficult to adapt to new equipment like washing machines, programmable air conditioners, and automatic telling machines (ATM), e-ticket, online banking and e-business, smart grids [6].

\section{A Mandate to Nowhere}

Television and computer laid down the foundation on which the mobile communication and internet superstructures were built. Mobile phones and the internet have unveiled all hidden secrets and shrunk the distances between the people and information irrespective of age and race. ICT networks are growing fast, and our dependence on electronic gadgets is exponentially rising day by day. Several new websites are open, and zillions of children browse internet daily. Moor's law has failed to predict the ultimate data rates, and e dominance is shifting from Western to Asian countries. Developments in internet data rate are touching to $\mathrm{THz}$ bandwidths $[7,8]$, and there is a thirst for more. Comparison of growing internet interconnectivity with nature is shown in Figure 2.

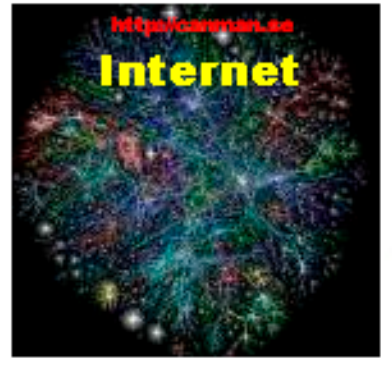

(a)

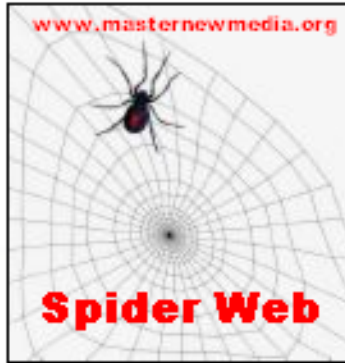

(b)

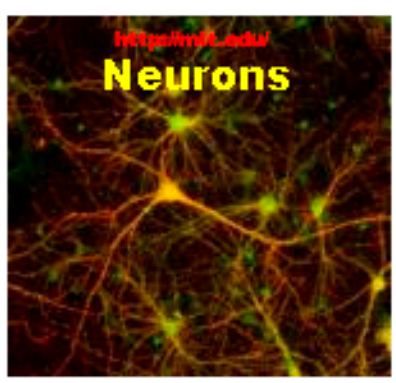

(c)

Figure 2. Interconnectivities of the internet, spider web and neurons: (a) Man's vision; (b) Insect made; (c) Nature made. 
Of course, ICT benefits are undisputed and irrefutable. Our children were born when these facilities had become part of our society. No doubt, we are still not adapted to e-environment, but our children are. Young children visit no man's lands (cyberspace) to which $80 \%$ of parents are not aware. Incidences of cyberspace incidences in Pakistan and other Asian countries are documented already. In situations where the parents and even teachers are not aware of the depth of associated risks, it becomes the duty of government and her agencies to protect their children in cyberspace as they protect their public against land, air and sea attacks. After nuclear, chemical and biological threats the internet has started posing virtual threats [9].

Children in cyberspace chat with unknown people without seeing their face. The e-predators disguise themselves as children and try to get children particulars and personal details. They send gifts to their home addresses and finally make appointments with them to abduct or abuse them. Our children in cyberspace are vulnerable to psychological threats as we are susceptible to social ills. Children in cyberspace need protections as they need during unaccompanied visits to strange lands. Children exposure to pornographic images and violent scenes imprint obscenity and cruelty towards their friends. Several kids trying wrestling injured other kids, imitating the guns have fired their parent's actual firearms, seeing internet videos have been attempting to do it themselves [6]. Cases have been noted where ordinary family men were found sexually harassing children $[7,8]$. It is a criminal offence to spread children pornographic images [9] as it is a mandate to nowhere.

\section{Children Protection in Cyberspace}

Thousands of cases have been reported on violence against children through internet [10]. The problem has become of even more grave concern in Muslim countries where coeducation is regarded as a sin and internet chat and access to pornographic images and videos is permitted to children from their homes [11,12]. Information about harms to children in cyberspace is disparate and clustered in communities where new technologies have become available to people at low cost. Secular and polytheist communities also have embedded risks, but Muslims children are too vulnerable to internet ills such as self-harm, bullying and pornography. ICT industry is ahead of governments and most communities, while many parents try to stay abreast of the latest Internet games their children are playing, at the very least, without genuinely grasping the intricacies. The plight of children of the illiterate parents is horrible. It becomes the duty of government to protect the innocent children through her ministry of information and communication technologies. We are Muslims and want to educate our children in an Islamic way. We do not want our children to go astray like Western secular countries. Decision and policy-makers within governments at various levels are supposed to have a responsibility to act for the protection of children in cyberspace exactly they act for other physical crimes. It is not obligatory rather a mandatory duty comply with.

Most children have integrated their life with a cell phone, video games and internet. Internet audio-video facilities expose the children to all bare evils and ills. Guidelines for parents have been published but what about parents who cannot operate a computer or browse the internet. Network operators, internet services providers (ISP) and law enforcing agencies with government mandate must work together to protect children in cyber space. I see children alone and helpless as a man among animals in jungles where he watches animals eat others alive. Pakistani children spend an average $15-17 \mathrm{~h}$ per week on computer games, cartoons and internet. 50-60\% of TV programs and video games are based on violence.

\section{Recommendations}

To try to suggest reforms to Chairman (PTA) or the Government of Pakistan is like sending Owls to Athens, but generation gap may allow me to focus PTA and government crosshairs on the origin of the ICT evolved virtual problem. As a greenhorn adviser, Wesuggest PTA and Government of Pakistan consider the following suggestions to ensure child protection in cyberspace.

1. National ICT policy must incorporate UNO existing laws to protect children in cyberspace.

2. Children need security in cyberspace as public needs security in daily life. 
3. A multidisciplinary research is required to protect children and save their time.

4. Convene a global children conference to share their bitter experiences in cyberspace.

5. Train law enforcement agencies in comprehending, detecting, and punishing ICT criminals.

6. Federal and provincial parliaments may design new laws against local and global ICT crimes.

7. Advise public to use parental control internet software such as parentalLog, CyberPatrol, CyberSitter and NetNanny etc. to keep an eye on children activities in cyberspace.

8. Use filtering devices in schools, homes and Internet cafes to protect children access to ugly web sites.

9. Develop chat room monitors to inform parents and law enforcing agencies in a time when children are under attack.

10. Public and utility protection may be enhanced by making transparent e-transactions and monitoring electronic intrusions.

11. The government may classify and control video games in the market and force CDs sellers to register their business.

12. Consider implementing Internet Safety Technical Task Force's Final Report on Child Safety \& Online Technologies.

\section{References}

1. Khan, N.; Goldwasser, S.M.; Abas, N.; Kalair, A.R.; Haider, A. Experimental investigation of unidentified helium-neon lasers. Appl. Opt. 2017, 56, doi:10.1364/AO.56.010030.

2. Khan, N.; Mariun, N.; Abas, N. Photon fuelled electric power plants. Lasers Eng. 2008, 18, 383-401.

3. Khan, N.; Saleem, Z.; Abas, N. Endorsement of new SI unit prefixes for space, time, energy and matter. Lasers Eng. 2008, 18, 107-118.

4. Khan, N.; Abas, N. Smart Crime science and Shabby Control Technologies. VFAST Trans. Educ. Soc. Sci. 2015, 6, 55-71.

5. Khan, N.; Abas, N.; Kalair, R. Electronic and Photonic Communiqué Bottlenecks Mandate Ultrafast Optics. Nonlinear Opt. Quantum Opt. 2017, 48, 185-192.

6. Khalil, H.B.; Abas, N. Smart grids: An approach to integrate the renewable energies and efficiently manage the energy system of Pakistan. In Proceedings of the International Conference on Computing, Communications and Networking Technologies, 11-13 July 2014; doi:10.1109/ICCCNT.2014.6963060.

7. Khan, N.; Abas, N.; Kalair, A.; Saleem, M.S. Experimental Study of Optical Fiber Conditions in Service on Data Communication. Nonlinear Opt. Quantum Opt. 2017, 48, 225-235.

8. Khan, N.; Abas, N.; Kalair, A. Design of an Optical Clock Repetition Rate Multiplier. Nonlinear Opt. Quantum Opt. 2016, 48, 17-28.

9. Ahmad, M.R.; Khan, N.; Hoong, C.C.; Abas, N. Remote data acquisition through internet based telemetry. In Proceedings of the Student Conference on Research and Development (SCORED 2003), Putrajaya, Malaysia, 25-26 August 2003; doi:10.1109/SCORED.2003.1459699.

10. Yasmin, M.; Sohail, A.; Mangrio, R.A. Myths Broken or Sustained: Representation of Women Victims in Pakistani Media. Open J. Soc. Sci. 2015, 3, 209-219, doi:10.4236/jss.2015.37033.

11. Yasmin M, Sohail A. A creative alliance between learner autonomy and English language learning: Pakistani University teachers' beliefs. Creatvity Studies 2018,11, 1-9. doi:10.3846/23450479.2017.1406874.

12. Yasmin, M., Naseem, F., Raza, M. Creative marginalization of gender: a discourse analysis of advertisements in Pakistani newspapers. Creativity Studies 2018, 11; 152-161; doi: 10.3846/cs.2018.5509. 